\title{
OPEN KUNTSCHER NAILING OF FEMUR SHAFT FRACTURE- ITS RELEVANCE IN PRESENT ERA OF INTERLOCK NAILING
}

\author{
Santosh Reang1, Sankar Deb Roy², Taranga Reang ${ }^{3}$
}

${ }_{1}^{1}$ Assistant Professor, Department of Orthopaedics, Agartala Government Medical College and GB Pant Hospital, Agartala, Tripura, India.

${ }^{2}$ Assistant Professor, Department of Orthopaedics, Agartala Government Medical College and GB Pant Hospital, Agartala, Tripura, India.

${ }^{3}$ Assitant Professor, Department of Community Medicine, Agartala Government Medical College and GB Pant Hospital, Agartala, Tripura, India.

ABSTRACT
BACKGROUND
Femur shaft fracture is a common injury seen in road traffic accidents and other high energy trauma. Kuntscher nailing was a
popular method of fixation before interlocking intramedullary nail has come into practice. However, in certain situations where
interlocking nail cannot be used, the role of Kuntscher nail is still a method to fix the fracture.

\section{MATERIALS AND METHODS}

This retrospective descriptive study was done to evaluate the relevance of Kuntscher nailing in femur shaft fracture against the interlocking intramedullary nail with regard to union, complication, return to work place. We retrospectively reviewed 73 patients with fracture shaft of femur treated with open Kuntscher nailing. Patients were discharged from the hospital after 14 days of surgery usually after removal of stitches.

\section{RESULTS}

All fractures healed within 16-24 weeks and the union rate was 96\% (95.89). 4 patients developed superficial wound infections. 3 had limb shortening of 1-2 centimeters and range of motion at the knee from 0 to 130 degrees at minimum 6 months follow up. There were no rotational deformities. 1 patient had bent nail because of early mobilization and 2 broken nails leading to nonunion. $54.79 \%(n=40)$ belonged to low socio-economy group and $6.8 \%(5)$ had medical co-morbidity.

\section{CONCLUSION}

Open Kuntscher nailing for fracture shaft femur is still a relevant surgery in the developing worlds, especially in a government set up where low socio-economic group patients form a major chunk of in-patients. It is found that K-nailing gives better functional and clinical results where interlocking nailing can't be done.

\section{KEY WORDS}

Kuntscher Nail, Intramedullary Nail, Femoral Shaft Fracture HOW TO CITE THIS ARTICLE: Reang S, Roy SD, Reang T. Open kuntscher nailing of femur shaft fracture- its relevance in present era of interlock nailing. J. Evolution Med. Dent. Sci. 2019;8(12):924-926, DOI: 10.14260/jemds/2019/205

\section{BACKGROUND}

Fracture of shaft of femur is a catastrophic event with an age and gender related bimodal distribution and occurs frequently in young men after high energy trauma and in elderly woman after a low energy fall. The most common causes of such trauma are road traffic accidents (RTA), fall from height and gunshots injuries. The incidence is on the rise due to increasing vehicular accident and rapid urbanization. ${ }^{1}$ Several methods of treatment of femoral shaft fracture is now available; the choice of a particular method being determined by the type, location, degree of comminution, age of the patient, surgeon expertise,

'Financial or Other Competing Interest': None.

Submission 09-01-2019, Peer Review 10-03-2019,

Acceptance 16-03-2019, Published 25-03-2019.

Corresponding Author:

Dr. Sankar Deb Roy,

Department of Orthopaedics,

Agartala Government Medical College and

GB Pant Hospital,

Agartala, Tripura, India.

E-mail:drsankar62@gmail.com

DOI: $10.14260 /$ jemds $/ 2019 / 205$ availability of implant and instrument and patients socioeconomic status. Though intramedullary K-nailing is a popular method of treatment in femoral shaft fracture in recent past, it has limited use in distal fracture due to anatomic configuration of that part of femur and following the introduction of interlocking nail. We have been doing lots of operation in our institute on fracture shaft of femur with various implants like intramedullary nail, interlocking nail, non-locking like K-Nail, plates, LCDCP. Locked plates etc., and interlocking IM nail is come out to be the best now a days. In spite of this fact we have used lots of k-nail in our institute, between 2012 - 2014. When Gerhard Kuntscher introduced the nail in 1940, it was considered revolutionary method in the management of femoral shaft fracture. ${ }^{2}$ In the past other methods of managing this type fracture have been describe like plaster, traction, encirclage wire, enders nail plates etc. 3,4 Our institution cater patient from all corner of the state having the population of more than $30 \mathrm{~K}$ and $60 \%$ belong to below poverty line (BPL). ${ }^{5}$ With this background we have done a retrospective descriptive study on 73 patients treated by open Kuntscher nailing at Agartala Government Medical College and GBP Hospital to whom we have operated between 2012 to 2014 to find out the efficacy of K-nail use in our institution against the other better and standard method 
and evaluate the outcome of open Kuntscher nail with regard to time to union, complication, return of patient to his work (Limb length and range of motion at the knee).

\section{MATERIALS AND METHODS}

A retrospectively data were collected for 73 patients who were operated in Orthopaedics Department of Agartala Government Medical College and GB Pant Hospital and used K-nail for internal fixation. Patients aged between 15-75 years who were treated by open k-nail were included. The data were collected from the year 2012 to 2014 .

\section{Method}

All were operated in routine Operation Theatre after initial clinical assessment, resuscitation. Investigations were done in the departmental laboratory of the hospital. All the patients were operated by standard method in the left lateral or right lateral position depending on the side of fracture on a standard fracture operating table. In some cases, a supplementary circumferential wring by SSG wire and unicortical plate (one) was used for comminuted fracture and fracture at lower third portion respectively. The degree of comminution of the fracture was graded using Win-Quist et al grading6.

Antibiotics were given for 10 days ( 3 days injectable and 7 days oral) and patients were mobilized non weight bearing on day 7. The average postoperative hospital stay was 14 days. Follow up was done in OPD. All patients were demonstrated and advised quadriceps exercise. Partial weight bearing with support was allowed after an average duration of 12 weeks.

\section{RESULTS}

All the wounds healed within 2 weeks, except 4(diabetic) which cellulites persisted for more than two weeks. There was no deep wound infection. All fractures healed in 16 to 24 weeks except 3 (Fig. $1 \& 2$ ).

There was no rotatory deformity and 2 nails fractured, one patient had bend nail (Fig. 3).

$3(4.1 \%)$ of the patients had shortening of limb by about 2 $\mathrm{cm}$. The duration of follow up was 12-18 months with an average of 15 months. The range of motion at the knee was 0 -130 degrees at 6 months of follow up. Fracture configuration was transverse in $45(61.6 \%)$ patients, short oblique in 20 $(27.4 \%)$ and comminuted in $8(11 \%)$ patients (Fig. 4) The degrees of comminution using Win-Quist et al classification are: 6 patients had type I, 2 had type II. There was involvement of the upper third femur in $20(27.3 \%)$ patients and middle third femur in $52(71.2 \%)$ patients and lower third femur in $01(1.3 \%)$. The SSG wire was applied in 6 patients with unstable fractures and 1 with a neutralizing plate. 4 patients had superficial wound infections which resolved completely with dressing and appropriate antibiotics. 10 (13.69\%) of the patients had associated minor injuries. Complete weight bearing commences on the average of 18.3 weeks onwards. $40(54.7 \%)$ patients belong to low socioeconomic family, 5 patients operated on high risk medical co-morbidity and 28 patient younger age group (Below- 20 yrs.)
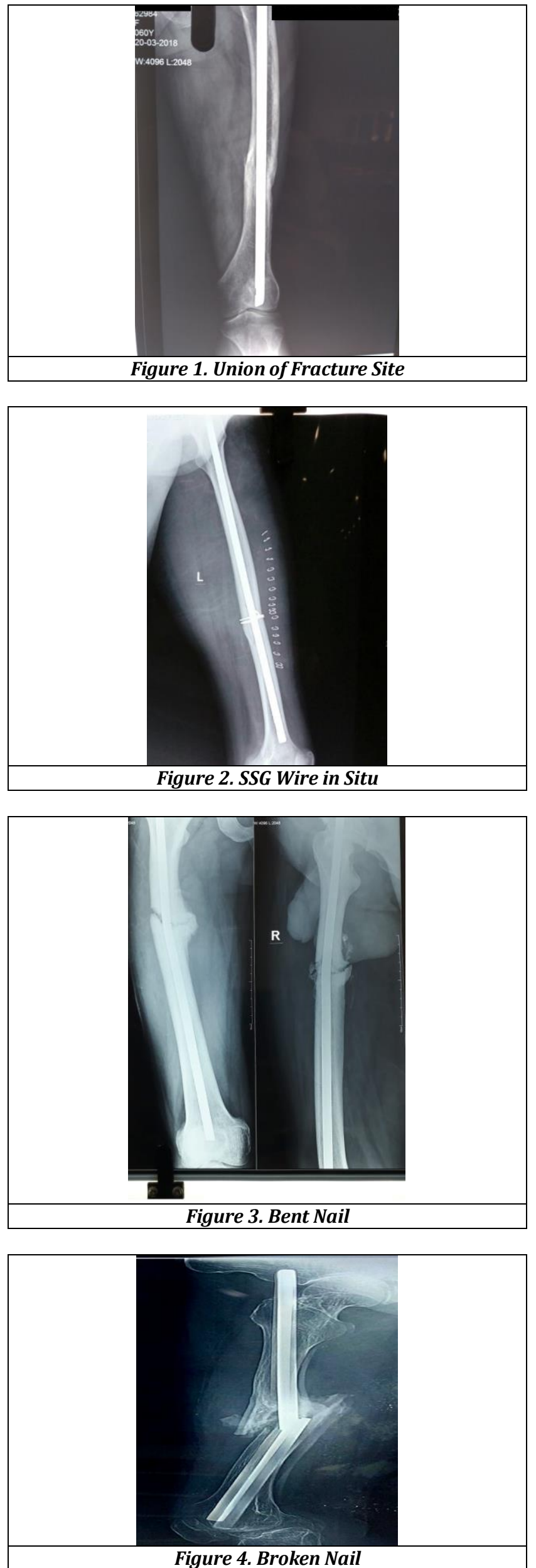


\section{DISCUSSION}

When Gerhard Kuntscher introduced the nail in 1940, it was considered revolutionary in the management of femoral shaft fracture. Open Kuntscher nailing for fracture shaft of femur is no longer preferred method in practice now a days, where closed interlocking nailing is considered the treatment of choice as other methods landed up with many complications. ${ }^{3-4}$ In spite of the drawback of k-nail we have used it in 73 numbers of patient and amongst them in 40 cases considered due to their financial status, 5 case due to medical co morbidity and in 28 surgeon choice belonging to younger group having fracture at isthmus. In ours study all the patients treated with open Kuntscher nailing had their fractures united on the average of 20 weeks with a range of 16 to 24 weeks. This was comparable to the findings by Davlin et al 7 at 20 weeks but longer than those reported by Devnani AS et al 8 that had union in their group of patients at 14 weeks and A S Bajwa et al ${ }^{9} 12-14$ weeks.

The interlocking nails also not devoid of complication as reported by some authors ${ }^{10,11}$ In this study only $3(4.1 \%)$ patients had 1-2 cms shortening. The fear of infection has always been there in open surgery hence recent trend is towards the closed surgery. In this study 4 (5.4\%) patients developed superficial wound infection that resolved with dressing and appropriate antibiotics. This was comparable to those reported by Blumback et al ${ }^{12}$ who reported 3-5 \%in 89 fractures and higher than Williams ${ }^{13}$ reports $2.4 \%$ in 42 fractures. However, their reports included only deep infections. The range of motion at knee ranged from 0 to 130 degrees at minimum six month of follow up. Non-union in the literature is reported to occur in-between $1.5 \%$ - $10 \%$ of cases. In our series, the infection rate was $5.4 \%$ and nonunion $4.1 \%$ due to implant failure which was addressed by other method.

\section{CONCLUSION}

Open Kuntscher nailing is still a relevant method which can be used in hospitals where very low socio-economic group patients form a major chunk of in-patients and also in very high risk patients in terms of prolonged exposure to anaesthetic agents and longer duration of operative procedure. However, this procedure is not to be recommended for highly comminuted fractures or when the fracture is in the distal third of the femur. While closed interlocking nail remains the gold standard in the treatment of femoral shaft fractures, open Kuntscher nailing may still have its relevance in the developing countries as reported by other author. ${ }^{14,15}$ Maruenda-Paulino JI et al $^{16}$ after their study concluded usefulness of Kuntscher nailing in children and adolescents with unstable high velocity fracture of the femoral shafts. It was concluded that open Kuntscher nailing is a method still relevant in situations like poor patients, high risk patients and when interlocking nailing of femoral shaft fracture may not feasible.

\section{REFERENCES}

[1] Koval KJ, Zuckerman JD. Handbook of fractures. $3^{\text {rd }}$ edn. Philadelphia: Lippincott Williams \& Wilkins 2006.

[2] Kuntscher G. The intramedullary nailing of fractures. Clinical Orthop Rel Res 1968;60:5-12.

[3] Johnson KD, Johnston DW, Parker B. Comminuted femoral-shaft fractures: treatment by roller traction, cerclage wires and an intramedullary nail or an interlocking intramedullary nail. J Bone Joint Surg Am 1984;66(8):1222-35.

[4] Webb LX, Gristina AG, Fowler HL. Unstable femoral shaft fractures: a comparison of interlocking nailing versus traction and casting methods. Journal of Orthopaedic trauma 1988;2(1):10-2.

[5] http://tspcb.tripura.gov.in/people.htm. (Accessed on 22/10/2018).

[6] Winquist RA, Hansen ST Jr, Clawson DK. Closed intramedullary nailing of femoral fractures. A report of five hundred and twenty cases. JBJS 1984;66(4):52939.

[7] Davlin L, Johnson E, Thomas T, et al. Open versus closed nailing of femoral fractures in the polytrauma patient. Contemp Orthop 1991;22(5):557-63.

[8] Devnani AS. Open reamed femoral intramedullary nailing - revisited. Eastern J Med 2003;8(1):7-11.

[9] Bajwa AS. Current indications for open Kuntscher nailing of femoral shaft fractures. East and Central Afn'can Journal of Surgey 2000;5(2).

[10] Sojbjerg JO, Eiskjaer S, Moller-Larsen F. Locked nailing of comminuted and unstable fractures of the femur. JBJS 1990;72(1):23-5.

[11] Tornetta P 3rd, Ritz G, Kentor A. Femoral torsion after interlocking nailing of unstable femoral fractures. J Trauma 1995;38(2):213-9.

[12] Blumback RJ, Ellison PS Jr, Poka A, et al. Intramedullary nailing of open fractures of the femoral shaft. JBJS Am 1989;71(9):1324-31.

[13] William MM, Askins V, Hinkes EW, et al. Primary reamed intramedullary nailing of open femoral shaft fractures. Clin Orthop Rel Res 1995;(318):182-90.

[14] Olasinde AA. Open Kuntscher nailing of closed femoral shaft fractures: revisited. The Internet Journal of Third World Medicine 2005;3(2).

[15] Manjhi LB, Suman SK, Kumar R, et al. Open interlocking nailing of the fracture of the shaft of femur. International Journal of Orthopaedics Sciences 2017;3(2):611-3.

[16] Maruenda-Paulino JI, Sanchis-Alfonso V, GomarSancho F, et al. Kuntscher nailing of femoral shaft fractures in children and adolescents. Int Orthop 1993;17(3):158-61. 